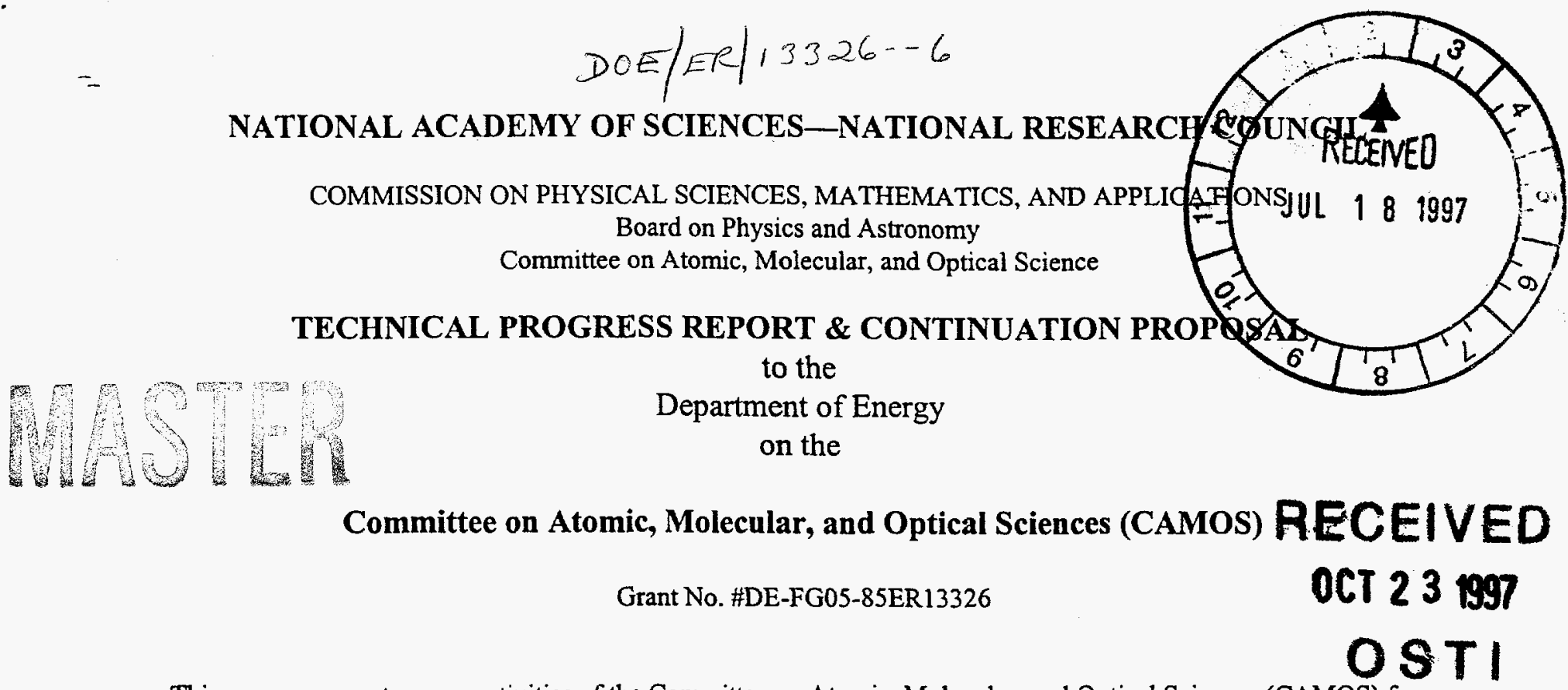

This progress report covers activities of the Committee on Atomic, Molecular, and Optical Sciences (CAMOS) for the period February 1, 1993 to January 31, 1994.

\title{
SUMMARY
}

The Committee on Atomic, Molecular and Optical Sciences (CAMOS) of the National Research Council (NRC) is charged with monitoring the health of the field of atomic, molecular, and optical (AMO) science in the United States. Accordingly, the Committee identifies and examines both broad and specific issues affecting the field. Regular meetings, teleconferences, briefings from agencies and the scientific community, the formation of study panels to prepare reports, and special symposia are among the mechanisms used by the CAMOS to meet its charge. This progress report presents a review of CAMOS activities from February 1, 1993 to January 31, 1994. The details of prior activities are discussed in earlier progress reports. This report also includes the status of activities associated with the CAMOS study on the field that is being conducted by the Panel on the Future of Atomic, Molecular, and Optical Sciences (FAMOS).

During the above period, CAMOS has continued to track and participate in, when requested, discussions on the health of the field. Much of the perspective of CAMOS has been presented in the recently-published report Research Briefing on Selected Opportunities in Atomic, Molecular, and Optical Sciences. That report has served as the basis for briefings to representatives of the federal government as well as the community-at-large. In keeping with its charge to monitor the health of the field, CAMOS launched a study designed to highlight future directions of the field.

\section{THE COMMITTEE}

The Committee on Atomic, Molecular, and Optical Sciences is a standing committee under the auspices of the Board on Physics and Astronomy (BPA), Commission on Physical Sciences, Mathematics, and Applications (CPSMA) of the National Academy of Sciences (NAS)--National Research Council. CAMOS is a multidisciplinary committee with membership drawn from universities, industry, government, and national laboratories. Areas of expertise on the committee include atomic physics, molecular science, and optical science. A special effort has been made to include a balanced representation from the three subfields. [See attached roster.]

The atomic, molecular, and optical sciences represent a broad and diverse field in which much of the research is carried out by small groups. These groups generally have not operated in concert with each other and, prior to the establishment of CAMOS, there was no single committee or organization that accepted the responsibility of monitoring the continuing development and assessing the general health of the field as a whole. CAMOS has accepted this responsibility and currently provides a focus for the AMO community that is unique and essential. 


\section{DISCLAMMER}

Portions of this docement may be illegible in electronic image products. Images are produced from the best available original document. 
The operating guidelines of the Committee, originally created in 1970, include the following: (1) to provide a source from which the federal agencies could obtain technical advice and assistance; (2) to initiate and oversee the conduct and publication of studies concerning atomic, molecular, and optical science and its multidisciplinary connections to other fields of science and technology; (3) to provide a forum for discussion among atomic, molecular, and optical scientists and, thereby, provide a unifying force in this diverse and varied field; and (4) to provide an interface for communication among the atomic, molecular, and optical science communities and federal agency program directors who fund research in the field. These objectives continue to serve as the guidelines for the committee and, in response, several mechanisms have been developed to achieve these objectives. In particular, CAMOS organizes and conducts special technical studies, surveys, workshops, and other meetings. CAMOS also functions as an oversight committee for ad hoc panels charged with the task of preparing reports on specific issues or topics. Symposia held at the National Academy of Sciences or at research centers have been used to focus attention on particular issues connected with facilities, programs, or other matters of concern to the AMO community. CAMOS continues to use these mechanisms to develop and undertake new projects.

CAMOS has conducted a number of studies related to the health of atomic and molecular science and is well prepared to respond to requests for studies on a broad array of topics and issues. Specific report-generating projects under the aegis of the CAMOS are separately proposed and funded as the committee identifies key issues itself or accepts requests from agencies of the government and develops corresponding activities.

\section{Highlights of Recent Meetings of the Committee}

Regular meetings of the Committee and special meetings with federal agency representatives and the scientific community are essential to maintaining continuous contact with both groups. The highlights of meetings held during the period February 1, 1992 to January 31, 1993 are presented below:

September 25, 1994 (Washington, DC). The primary business items on the agenda were the following: (1) a review of the conclusions and recommendations of the report on the Future of Atomic, Molecular, and Optical Sciences (FAMOS), (2) a discussion on disseminating the FAMOS report, and (3) plans for the upcoming Workshop on Database needs for Plasma Processing and Simulation. A portion of the agenda was devoted to informal discussions with agency representatives from DOE and NSF.

October 6, 1994 (Dallas, TX). This was a follow-up meeting to the September, 1994 meeting involving representatives of both CAMOS and FAMOS. This meeting was held in conjunction with the Tenth Interdisciplinary Laser Science Conference (ILS-X)/1994 OSA Annual Meeting.

In addition to these meetings, Committee members made presentations to agency representatives, the scientific community, or other groups on matters of importance to the AMO community-at-large during this reporting period.

\section{STATUS OF CAMOS PROJECTS}

\section{Summary}

Over the past several years, CAMOS initiated or completed several projects. The Panel on the Future of Atomic, Molecular, and Optical Sciences, operating under the auspices of CAMOS, has almost completed its assessment of the scientific and technological developments and opportunities in the field. The study will both assess the state of knowledge in AMO science and also lay out priorities of the community in pursuing its research agenda over the next several years.

In addition, CAMOS has undertaken several other projects, including the following:

- Optical Sciences and Engineering Study

c

- Workshop on Database Needs for Plasma Processing of Materials 
The current status of these projects bears directly on the activities of CAMOS during the performance period for this contract.

\section{Initiation of a Study on Optical Sciences and Engineering}

CAMOS representatives worked together with members of FAMOS and the BPA to hold a program initiation meeting on March 19-21, 1993 to determine the desirability and need of a broad study on optical sciences and engineering. Based on the outcome of the program initiation initiative, a proposal in this area has been prepared and submitted to NIST, ARPA and NSF.

\section{Workshop on Database Needs for Plasma Processing of Materials}

CAMOS is sponsoring, jointly with the Plasma Science Committee (PLSC) of the NRC, a workshop on database needs for plasma processing of materials. The need for an improved database was identified in the recent NRC report Plasma Processing of Materials: Scientific opportunities and Technological Challenges. The purpose of the workshop would be to bring a small group of experts together so that they may develop a specific, prioritized list of needs, appropriate action items, and an assessment of the potential impact on technology. Workshop participants would be expected to create a matrix that relates processes to the most important data base and diagnostic needs. Topics would include the following: electron and ion impact ionization, dissociation, and excitation cross sections; ion transport cross sections, particularly in the energy range from $1 \mathrm{eV}$ to $100 \mathrm{eV}$; ion molecule reaction cross sections for ion energies in the same energy range; database generation and dissemination; theoretical capability; experimental capability; surface reaction probabilities and surface kinetics for free radicals, ions, and electrons; state-of-the-art plasma process simulation and plasma reactor design; and state-of-the-art plasma diagnostic capabilities. It is anticipated that the workshop will be held in April, 1995.

\section{The Future of Atomic, Molecular, and Optical Sciences}

Following the preparation of the report Research Briefing on Selected Opportunities in Atomic, Molecular, and Optical Sciences, CAMOS proposed that a detailed study on the scientific and technological opportunities of the field be conducted to assess the state of knowledge of the field of atomic, molecular, and optical science and to identify the priorities of the community in pursuing its research agenda over the next several years. The project received sufficient funding (from DOE, NSF, AFOSR, and NASA) and is now underway. The formal charge to the Panel on the Future of Atomic, Molecular, and Optical Sciences includes the following:

- Determines manpower, instrumentation, facility, and funding requirements not only in the context of the intellectual challenges of AMO science, but also in the context of national needs such as (a) science education; (b) defense, energy, space, and environmental applications; (c) industrial and technological competitiveness; and (d) appropriate aspects of human health and welfare.

- Seeks to identify scientific forefronts, technological opportunities, and windows of future opportunity.

- Seeks to establish sets of research and educational priorities from various perspectives.

- Sets forth goals and planning scenarios that reflect these research and educational priorities.

- Develops long-range strategies that will best meet the goals set forth.

- Assesses the institutional infrastructure in which AMO science is conducted and identifies changes that would improve its constituent research and educational efforts.

- Provides a comparison of AMO science in the United States with its counterpart in other industrialized nations.

- Reviews the scientific advances made during the last decade.

In addressing the charge, FAMOS has solicited input from many segments of the community. For example, letters were sent to key AMO scieftists and professional organizations. The Panel wrote to over 300 AMO scientists requesting comments and input that could be used to address the charge. The responses generally endorsed the efforts of the Panel as well as pointed to a field of excitement and opportunity. Also, letters were written to the officers of the American Physical Society's (APS) Division of Atomic, Molecular, and Optical Physics 
(DAMOP), Division of Chemical Physical (DCP), Laser Science Topical Group (LSTG); IEEE Lasers and ElectroOptics Society; Optical Society of American (OSA); and others requesting advice on matters that warranted attention by the Panel, requesting help with publicity through society newsletters and at meetings, and requesting input on any of the issues outlined in the charge. To reach members of the AMO community-at-large, the Panel developed and conducted an extensive survey. The survey was designed in consultation with survey experts at the NRC Office of Scientific and Engineering Personnel (OSEP). Over 20,000 questionnaires were mailed to atomic, molecular, and optical (AMO) PhD scientists throughout the United States. The AMO scientists were identified from the membership lists of several professional societies, including, the American Physical Society, the American Chemical Society, the Materials Research Society, the Optical Society of America, IEEE/Lasers and Electro-optics Society, and SPIE. Tabulation and analysis of the results has required a large amount of effort from the Panel.

As oversight committee for the panel, CAMOS continues to assist the Panel in addressing the charge.

Following completion of the study, CAMOS will actively promote and disseminate the results of the study. The report is expected to be published in early 1994.

\title{
Attachments
}

(1) Roster of the Committee on Atomic, Molecular, and Optical Sciences (CAMOS)

(2) Roster of the Panel on Future Opportunities in Atomic, Molecular, and Optical Sciences (FAMOS)

\section{DISCLAIMER}

\begin{abstract}
This report was prepared as an account of work sponsored by an agency of the United States Government. Neither the United States Government nor any agency thereof, nor any of their employees, makes any warranty, express or implied, or assumes any legal liability or responsibility for the accuracy, completeness, or usefulness of any information, apparatus, product, or process disclosed, or represents that its use would not infringe privately owned rights. Reference herein to any specific commercial product, process, or service by trade name, trademark, manufacturer, or otherwise does not necessarily constitute or imply its endorsement, recommendation, or favoring by the United States Government or any agency thereof. The views and opinions of authors expressed herein do not necessarily state or reflect those of the United States Government or any agency thereof.
\end{abstract}


NATIONAL RESEARCH COUNCIL

$=\quad$ COMMISSION ON PHYSICAL SCIENCES, MATHEMATICS, AND APPLICATIONS

2101 Constitution Avenue Washington, D.C. 20418

BOARD ON

PHYSICS AND ASTRONOMY

(202) 334-3520

FAX: (202) 334-2791

INTERNET: BPA@NAS.EDU

\section{COMMITTEE ON ATOMIC, MOLECULAR, AND OPTICAL SCIENCES}

Terms expire on June 30 of year indicated.

William Stwalley, Chair 1997

Department of Physics

University of Connecticut

2152 Hillside Road, U-46

Storrs, CT 06269-3046

203-486-4924

Fax: 203-486-3346

Email: stwalley@uconnvm.uconn.edu

Daniel J. Larson, Past Chair 1995

Department of Physics

McCormick Road

University of Virginia

Charlottesville, VA 22901

804-924-6782, 6794

Fax: 804-924-4576

Email: djl@virginia.edu

NAS Steven Chu 1995

Physics Department

Stanford University

Stanford, CA 94305

415-723-3571

$=$ Fax: $415-723-9173$

Patricia M. Dehmer 1997

Argonne National Laboratory

Building 203

Argonne, IL 60439

708-252-4187

Fax: 708-252-7415

Email: pmdehmer@anl.gov

Robert W. Field 1996

Department of Chemistry, 6-219

Massachusetts Institute of Technology

Cambridge, MA 02139

(617) 253-1489

Fax (617) 253-7030
Daniel Grischkowsky 1996

Oklahoma State University

School of Electrical \& Computer Engineering

202 Engineering South

Stillwater, OK 74078

405-744-6622

Fax: 405-744-7554

Email: grischd@master.ceat.okstate.edu

Tony F. Heinz 1997

IBM Corporation

T.J. Watson Research Center

P.O. Box 218

Yorktown Heights, NY 10598

914-45-2333

Fax: 914-945-3715

Email: heinz@watson.ibm.com

Wendell T. Hill, III 1996

Institute for Physical Science and Technology

University of Maryland

College Park, MD 20742-2431

301-405-4813

Fax: 301-314-9404

Email: wendell_hill@umail.umd.edu

Paul S. Julienne 1997

National Institute of Standards and Technology

B268 Physics Building

Gaithersburg, MD 20899

301-975-2596

Fax: 301-975-3038

Email: paul@molphys.nist.gov

H. Jeffrey Kimble 1997

California Institiute of Technology

Norman Bridge Laboratory of Physics 12-33

Pasadena, CA 91125

(818) 395-8340

Fax: (818) 793-9506

Email: hjkimble@juliet.caltech.edu 
Siu Au Lee 1996

Department of Physics

Colorado State University

Fort Collins, CO 80523

303-491-6389

Fax: 303-491-7947

Email: salee@lamar.colostate.edu

C. William McCurdy, Jr. 1996

National Energy Research Supercomputer Center

P.O. Box 5509, L-561

Lawrence Livermore National Laboratory

Livermore, CA 94551

510-422-6383

Fax: 510-422-1482

Email: mccurdy@nersc.gov

Mara G. Prentiss 1997

Jefferson Laboratory 351

Harvard University

Department of Physics

Cambridge, MA 02138

617-495-4327

Fax: 617-495-0416

Email: mara@atomsun.harvard.edu

NAS David J. Wineland 1996

National Institute of Standards and Technology,

Division 847.10

325 Broadway

Boulder, CO 80303

$=\quad 303-497-5286$

Fax: 303-497-7375

Email: djw@enh.nist.gov

\section{NRC Staff}

Donald C. Shapero, Director

Email: dshapero@nas.edu

Daniel F. Morgan, Program Officer

Email: dmorgan@nas.edu

Board on Physics and Astronomy

National Research Council

2101 Constitution Avenue

Washington, DC 20418

202-334-3520

Fax: 202-334-2791

Email: bpa@nas.edu 


\section{NATIONAL RESEARCH COUNCIL}

\section{COMMISSION ON PHYSICAL SCIENCES, MATHEMATICS, AND APPLICATIONS}

2101 Constitution Avenue Washington, D.C. 20418

BOARD ON

(202) 334-3520

FAX: (202) 334-2791

PHYSICS AND ASTRONOMY

EMAIL: BPA@NAS.EDU

\section{PANEL ON THE FUTURE OF ATOMIC, MOLECULAR, AND OPTICAL SCIENCES}

All terms end on June 30, 1994.

Gordon H. Dunn (Chair)

Joint Institute Laboratory for Astrophysics

Campus Box 440

University of Colorado

Boulder, CO 80309-0440

(303) 492-7824

Fax: (303) 492-5235

Email: gdunn@jila or gdunn@jila.colorado.edu

Lloyd Armstrong, Jr.

Provost

University of Southern California

ADM 102-4019

University Park

Los Angeles, CA 90089-4019

(213) 740-2101

Fax: (213) 740-7606

Email: ARMSTRO @ Mizar.USC.EDU

Louis E. Brus

AT\&T Bell Laboratories

600 Mountain Avenue

$=\quad$ Murray Hill, NJ 07974

(908) 582-3119

Fax: (908) 582-3958

Sylvia T. Ceyer

Department of Chemistry

Massachusetts Institute of Technology

Building 6-225

Cambridge, MA 02139

(617) 253-4537

Fax: (617) 253-7030

Email: stceyer@athena.mit.edu

F. Fleming Crim

Department of Chemistry

University of Wisconsin

1101 University Avenue

Madison, WI 53706

(608) 263-7364

Fax: (608) 262-0381

Email: fcrim@chem.wisc.edu
Alexander Dalgarno

Harvard-Smithsonian Center for Astrophysics

60 Garden Street

Cambridge, MA 02138

(617) 495-4403

Fax: (617) 495-5970

Email: dalgamo@cfa

F. Barry Dunning

Rice University

P.O. Box 1892

Houston, TX 77251

(713) 527-8101, ext. 3544

Fax: (713) 285-5143

Email: fbd@spacsun.rice.edu

NAE Elsa M. Garmire

Center for Laser Studies

University of Southern California

University Park 1112

Los Angeles, CA 90089-1112

(213) 740-4238

Fax: (213) 740-8158

Email: garmire@mizar.usc.edu

Paul L. Kelley

Electro-Optics Technology Center

Tufts University

4 Colby Street

Medford, MA 02155

(617) 627-3136

Fax: (617) 627-3151

Email: pkelley@jade.tufts.edu

Daniel J. Larson

Department of Physics

McCormick Road

University of Virginia

Charlottesville, VA 22901

(804) 924-6782, 6794

Fax: (804) 924-4576

Email: djl@virginia 
All terms end on June 30, 1994.

Paul Liao

Chief Architect

Network Fundamentals, Architecture, and Planning

Network Systems Research Laboratory

Bellcore

331 Newman Springs Road, Room $3 Z 333$

Red Bank, NJ 07701-7040

(908) $758-3100$

Fax: (908) 758-4371

Email: liao@troy.cc.bellcore.com

Stephen R. Lundeen

Professor of Physics

Department of Physics

Colorado State University

Fort Collins, CO 80523

(303) 491-6647, -2510 lab

Fax: (303) 491-7947

Email: lundeen@lamar.colostate.edu

Thomas J. McIlrath

Institute of Physical Sciences and Technology

University of Maryland

College Park, MD 20742

(301) 405-4814

Fax: (301) 314-9404

Email: tjm@ipst.umd.edu

Peter W. Milonni

Los Alamos National Laboratory

Mail Stop B212

Los Alamos, NM 87545

(505) 667-7763

Fax: (505) 665-6229

Email: pwm@photon.lanl.gov

Richard C. Powell

Optical Sciences Center

University of Arizona

Tucson, AZ 85721

(602) 621-6997

Fax: (602) 621-9613

\section{NRC Staff}

Donald C. Shapero, Director

Email: dshapero@nas

Ronald D. Taylor, Senior Program Officer Email: rtaylor1@nas

Board on Physics and Astronomy

National Research Council

2101 Constitution Avenue

Washington, D.C. 20418

(202) $334-3520$

Fax: (202) 334-2791

Email: bpa@nas 
PROGRESS REPORT

to the

Department of Energy

on the

Committee on Atomic, Molecular, and Optical Sciences

Activities for February 1, 1988 to January 1, 1991

Grant No. DE-FG05-85ER13326

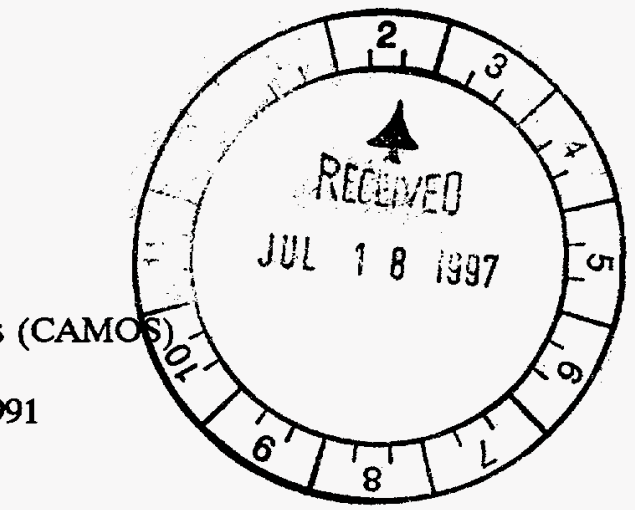

The Committee on Atomic, Molecular, and Optical Sciences (CAMOS) is a standing committee under the auspices of the Board on Physics and Astronomy, Commission on Physical Sciences, Mathematics, and Applications of the National Academy of Sciences--National Research Council. The atomic, molecular, and optical (AMO) sciences represent a broad and diverse field in which much of the research is carried out by small groups. These groups generally have not operated in concert with each other and, prior to the establishment of CAMOS, there was no single committee or organization that accepted the responsibility of monitoring the continuing development and assessing the general health of the field as a whole. CAMOS has accepted this responsibility and currently provides a focus for the AMO community that is unique and essential. The membership of CAMOS is drawn from research laboratories in universities, industry, and government. Areas of expertise on the committee include atomic and molecular physics, chemical physics, quantum optics, and materials science. A special effort has been made to include representation from the chemical physics and physical chemistry communities. CAMOS has conducted a number of studies related to the health of atomic and molecular science and is well prepared to respond to requests for studies on specific issues.

CAMOS was originally created (in 1970) with the following objectives: (1) to provide a source from which the federal agencies could obtain technical advice and assistance; (2) to conduct and publish studies concerning atomic, molecular, and optical science and its multidisciplinary connections to other fields of science and technology; (3) to provide a forum for discussion among atomic, molecular, and optical scientists and, thereby, provide a unifying force in this diverse and varied field; and (4) to provide an interface for communication among the atomic, molecular, and optical science communities and federal agency program directors who fund research in the field. These objectives continue to serve as the guidelines for the committee and, in response, several mechanisms have been developed to achieve these objectives. In particular, CAMOS organizes and conducts special technical studies, surveys, workshops, and other meetings. When appropriate, CAMOS functions as an oversight committee for ad hoc panels charged with the task of preparing reports on specific issues or topics. Symposia held at the National Academy of Sciences or at research centers have been used to focus attention on particular issues connected with facilities, programs, or other matters of concern to the AMO community. CAMOS continues to use these mechanisms to develop and undertake new projects.

\section{Standing Committee Meetings}

In accordance with its efforts to monitor continuing developments in the field of AMO science and to respond quickly to inquiries from federal agencies, CAMOS attempts to meet twice a year. During the performance period of the contract, CAMOS met on the following dates (all meetings were held at the National Research Council in Washington, D.C. unless otherwise noted):

1. April 1988

2. November 14, 1988

3. April 18, 1989

4. October 6, 1989

5. May 20, 1990 (This meeting was held in Monterey, CA in conjunction with the American Physical Society (APS) Division of Atomic, Molecular, and Optical Physics (DAMOP) Meeting. Additional activities are discussed below.)

6. December 7, 1990 (This meeting is scheduled to be held at the NRC.) 
Projects Completed During the Performance Period

Over the past three years, CAMOS continued to produce reports on issues of importance to AMO science. In particular, several studies were completed and the following reports were published:

1. Ion Storage Rings for Atomic Physics Research (1988)

2. Workshop on Molecular and Cluster Beam Science (1988)

In accordance with NRC policy, these reports were distributed or made available to the sponsors, committee and panel members, and to the general public without restriction.

CAMOS also spent considerable time and effort involved in followup activities (distribution, dissemination, and briefings) for reports published under the preceding contract. In particular, these activities focused on the results presented in the following reports:

1. Report of a Workshop on VUV and X-Ray Sources for Atomic and Molecular Science (1986)

2. International Survey of Atomic and Molecular Science 1984-1985 (1987)

3. The State of Theoretical Atomic, Molecular, and Optical Sciences in the United States (1987)

Status of Projects Initiated During the Performance Period

During this period CAMOS initiated the following projects:

1. Industrial Survey

2. Workshop on Exotic Atoms and Molecules

3. Survey of AMO funding

4. Survey of AMO experimentalists

5. Assessment of Future Opportunities in Atomic, Molecular, and Optical Physics

6. Update of AMO science Directory

1. Following discussion on the relationship between AMO science and industrial needs, CAMOS initiated an industrial survey. The committee felt that the results of this survey would clarify the usefulness of AMO scientists to industry. After the development of a questionnaire and an attempt to implement the project, it was decided that the industrial survey be discontinued because getting reliable information from industry had proven too difficult. However, it is planned that some additional effort to address this topic will be part of the assessment described below.

2. Motivated by a presentation by Ryszard Gajewski, Director of the DOE's Office of Advanced Energy Projects, describing projects involving muon-catalyzed fusion, CAMOS formulated plans for a workshop on the physics of exotic atoms and molecules. This workshop was to address concerns regarding the technical feasibility of work in this area and the advisability of continuing support by DOE for this research. Lack of supplemental funding for the workshop prevented further action.

3. In an effort to profile funding in the AMO sciences, CAMOS gathered preliminary information on detailed levels of support provided by different agencies. The classification of which components of an agency's overall program fall into AMO categories proved to be a complex problem. For example, support for areas such as surface science and quantum chemistry was difficult to evaluate in this context. Another example is the extent to which support for physical chemistry falls into this category. However, the committee felt that this problem was not insurmountable. This project has evolved into one component of the broader assessment described below.

4. In response to concerns over the current status and health of the experimental segment of AMO science, CAMOS developed and distributed a questionnaire to a specific group of the research community. Evaluation of the data is pending. This project will be broadened and included in the assessment described below.

5. CAMOS has responded to concerns about some of the above issues by developing plans for a major assessment of future opportunities in the field. The community of AMO scientists has indicated that it is their view that AMO physics is in critical need of a comprehensive assessment that can serve as an education and research planning guide for the 1990 s for use by federal agencies, national and industrial laboratories, individual investigators, and students. In response, CAMOS has devoted much of its effort in the past two years in planning for and organizing a detailed assessment of future opportunities in atomic, molecular, and 
optical sciences. This project is in an advanced stage of development and supplemental funding is currently being sought. The proposed assessment is discussed further below.

6. Finally, CAMOS developed plans to institutionalize the regular updating of the Directory of Atomic, Molecular, and Optical Scientists in the United States. First issued in 1981, the directory of atomic and molecular scientists contained the names, addresses, and research interests of more than 4000 atomic and molecular scientists in the United States. Consequently, it has been widely utilized because of its demographic value, its usefulness in locating scientists, and its value in characterizing their specialties. In 1986 an updated directory was published which included optical scientists. CAMOS has continued to attempt to make the directory as complete as possible by, for instance, comparing the listing with the membership roll of the Division of Electron and Atomic Physics of the American Physical Society, and other similar sources. The most recent listing (numbering 4750 entries) resides on a data base system within the NRC Board on Physics and Astronomy. Currently, plans are underway to establish the updating of the directory as a cooperative effort with the American Institute of Physics.

Special Meeting and Workshops

As part of its efforts to develop the assessment discussed above, CAMOS participated in several special meetings.

1. DOE Workshop on Future Opportunities for Research in Atomic, Molecular, and Optical Sciences, March 27, 1990, National Academy of Sciences, Washington, D.C. - CAMOS co-sponsored this workshop with DOE.

2. DAMOP Town Meeting on Future Opportunities in Atomic, Molecular, and Optical Physics, May 23, 1990, Monterey, CA - CAMOS co-sponsored this discussion of the results of the two DOE workshops and solicit community input for continuation of a broader assessment of the field.

Plans for the Assessment of Future Opportunities in Atomic, Molecular, and Optical Physics

Under CAMOS auspices, the proposed assessment will be guided by a broadly based panel that will conscientiously seek the involvement of all segments of the AMO community through the use of workshops, town meetings, and surveys of experimental and theoretical constituents. Recent developments in AMO physics and allied fields will be reviewed, resource and manpower needs will be assessed, windows of opportunity will be proposed, and future goals will be suggested. The panel will present the findings of the community in a brief report, which will be disseminated widely throughout the various branches of government, undergraduate and graduate educational institutions, and public and private research laboratories.

As noted above, this assessment will rely on activities initiated by CAMOS during the performance period of this contract. For example, the panel will conduct a survey of experimental AMO scientists in order to determine the current status and health of the experimental segment of the AMO research enterprise. A preliminary survey, containing financial, scientific, and demographic questions, was designed by CAMOS and has already been distributed to many members of the field. To date, over 250 responses have been received. The data will supplement the information about the status of AMO theory, which was gathered in a CAMOS study carried out a few years ago.

In formulating recommendations, the panel will make use of the reports of two DOE-sponsored workshops (the second one was cosponsored with CAMOS) that were conducted during 1989-90, as well as the recorded proceedings of the May 1990 DAMOP Monterey "town meeting" that was held to provide a public forum for the discussion of the workshop reports and to provide a mechanism for greater community involvement. Since the workshops were based upon divisions of AMO science into subfields that were particularly relevant to the mission of $\mathrm{DOE}$, the panel will probably have to reorganize the information collected and the recommendations developed into a framework that is more reflective of the general breadth of AMO physics. Moreover, since the DOE workshops were restricted in scope, one more will probably workshop be held during 1990-91 to provide coverage of additional topics, with a final "town meeting" scheduled for the April 1991 DAMOP meeting in Washington, DC, to ensure maximum community participation. In addition, the panel shall take full advantage of all information compiled by the American Physical Society in the development of its open notebooks on the status of physics. 
In an effort to assess more accurately the extent of AMO research in the country, the panel will retrieve appropriate information from the various national laboratories and make optimal use of the NSF data base, which is already in the process of being developed to provide such insight. Finally, although the information garnered may be very imperfect, it is envisioned that the panel will attempt to determine the extent to which AMO research is currently being conducted in industrial laboratories. This study is viewed as the major component of CAMOS's activities. Following completion of the study by the independent panel, CAMOS will actively promote and disseminate the results of the study. 